\title{
Preparing Teacher Candidates Using a Collaborative Residency Model
}

\author{
Dr. Karen S. DiBella \\ Dr. Kimberly G. Williams \\ Dr. Tammie T. Patterson \\ Mr. Texas Culver \\ Dr. Amanda Batts \\ Ms. Abbie McClure \\ Ms. Staci Fuqua \\ Educational Studies \\ University of Tennessee at Martin \\ United States
}

\begin{abstract}
Extensive field experiences can significantly impact the preparation of teacher candidates. Living in a high-stakes era of accountability, education reform efforts have shifted toward educator preparation programs. Such programs are being examined to measure whether they are preparing effective teacher candidates who are ready for today's classrooms. In fact, the current accrediting body for teacher education programs, Council for the Accreditation of Educator Preparation (CAEP), seeks to advance equity and excellence in education. Institutions of higher education and their partnering local education agencies understand the importance of clinical partnerships, purposeful placements, and reflective practices as they relate to teacher preparation. This study sought to create a pilot teacher residency model in an effort to make continuous improvements to the educator preparation program and prepare highly effective teachers.
\end{abstract}

Keywords: teacher preparation, residency, field experiences

\section{Introduction}

A team of university faculty members sought to improve the experiences and preparation of teacher candidates through a collaborative and targeted approach in the development of a teacher residency model for undergraduate PreK-3 and K-5 elementary licensure programs. The team collaboratively co-planned curriculum, assignments, and placements in an effort to better prepare teacher candidates as they transition from students to novice practitioners. Interviews, informal discussions, and formal meetingswere essential components of this study. Findings from this pilot group have provided faculty and partnering districts with critical insights into how to improve communication, content pedagogy, and field experiences in an effort to graduate and employ effective teachers respectively.

\section{Review of Literature}

Teacher preparation is at the forefront of current education reforms; it is critical to prepare highly effective teachers who are ready to take on the challenges of today's schools. Many states struggle to recruit and retain effective teachers, especially in urban and rural districts(Guha, Hyler, \& Darling-Hammond, 2017).Alarmingly, untrained novice teachers are likely to leave the profession after the first year and three times the rate of those who have had student teaching experience and completed a preparation program (Ingersoll, Merrill, \& May, 2014).That being said, it is becoming increasingly important that teacher preparation programs provide effective field experiences, model research-based instructional strategies, and seek continuous improvement. Accreditation and state initiatives collectively, seek to better align K-12 school practices with higher education (Gardiner \& Salmon, 2014). 
It is up to teacher education programs to answer the call. Co-planning, co-creating, and co-assessing need to become part of educator preparation programs; gone are the days of working independently in silos. While content knowledge and candidate quality are important, clinical field experiences are critical for future teachers (Weber, Waxman, Brown, \& Kelly, 2016). It is evident that university faculty need to evaluate programmatic needs, including curriculum, and standards-based instruction, as well as co-construct field experiences that will better prepare teacher candidates. Field experiences are often considered the opportunity for teacher candidates to integrate theory and practice as they work to improve their craft (Hughes \& McCartney, 2015). It is here that the deliberate pairing of teacher candidates with effective classroom teachers, who can also serve as highly effective mentors should be sought. It is important that cooperating teachers (CTs) understand and model the dispositions, skills, and knowledge that teacher candidates should develop (Ewert \& Straw, 2005). The role of the CT is to support the transition as the teacher candidate develops into a professional teacher (Weber, et al., 2016). Meaningful relationships, collaboration, and cooperative trainings are of critical importance as discussions ensue and pairings are planned.

Research suggests that when residencies are well-designed and well-implemented, they can create significant long-term benefits for districts, schools, and more importantly, the students (Guha, et al., 2017). Courses are often designed and taught by university faculty who are involved in local schools and are former teachers themselves (Guha, et al., 2017). In this study, all university residency faculty were previous classroom teachers and were currently teaching the methods courses in the teacher preparation program. They met on several occasions to plan course design, critical assessment tasks, and overall expectations of the residency placements. In addition, faculty kept copious notes and met periodically throughout the residency to monitor candidate development, discuss placements, CT pairings, and reflect on the overall experience in an effort to provide ongoing improvements as needed.

\section{Overview of the Study}

Candidates in the PreK-3 and K-5 programs represent the majority of teacher education program completers annually. Employer Satisfaction, as well as Program Completer Survey data for the last two years, consistently indicates two main areas for refinement as it relates to program improvement. The areas specified for consideration are longer length of classroom experiences during field placement and secondly, adjustment to placement timelines that allow students to begin field placements when the school district calendar year begins. In an effort to respond to district partners and candidate needs, the university faculty developed a Residency I model which was implemented in fall 2018. This model provided a redesign of the previous structure of field experiences in an effort to increase the amount of direct student contact from 75 hours when enrolled in methods coursework to 300 hours for the Residency I experience. Additionally, candidates were provided with consistent placements in the field throughout the term. The exceptional increase in field hours proves vital to preparation candidates needed for successful program completion.

Students applied for and enrolled in Residency I the semester before student teaching. The students were assigned two placements (different schools) based on a declared major providing diverse candidate/student experience. One placement in lower grades (PreK-2) and the other placement occurred in upper grades $\left(3^{\text {rd }}, 4^{\text {th }}\right.$, or $\left.5^{\text {th }}\right)$. In collaboration with school partners, students were required to attend the "first days of school" at the assigned first placement, allowing approximately three additional weeks in the field to gain first-hand knowledge of classroom set-up and organizational structures beginning day one. After the three-week experience, students attended four weeks of content instructional methods on campus. Content included literacy strategies, math/science/social studies/language arts content, pedagogy, and edTPA preparation. Students officially began the first placement at the assigned school district to complete a three-week Monday-Friday placement routine. At the conclusion of the first placement, students returned to campus for additional course content training and then transitioned to the second placement for a four-week experience prior to returning to the campus classroom to complete content coursework and debrief the Residency I experience.

Faculty and partner collaboration on the design of the two-placement model was instrumental to the success of the first cohort. School districts were extremely supportive of utilizing the Residency I placements as the candidates transitioned to student teaching the following term. The second placement for Residency I became the candidates' first student teaching placement. This seamless transition from Residency I to student teaching was expected to have a positive impact on student edTPA performance due to the familiarity of the setting. 
Likewise, the first Residency I placement became the second placement in student teaching, again supporting candidate/student/teacher familiarity during high stakes testing occurring among districts at the time of the placement. University faculty and field placement coordinator debriefed with school district personnel at the end of the Residency I semester and will conduct a final debrief at the end of the student teaching semester. The continuation of co-planning between university faculty and cooperating teachers for future Residency I terms will play a key role in ensuring that common goals are achieved and candidates are best prepared for entry into the profession.

\section{Methodology}

In order to examine teacher candidates' views of Residency I experience, a convenience sample of participants from one university and two off-campus sites were chosen and surveyed at the mid-point of their residency experience. The participants in this study represented students in their senior year of the education program. These students were selected for this study because they constitute the first cohort of students to have the Residency I experience as part of their educational program. All participants were enrolled in an educator preparation program throughout their education experience at two off-campus sites and the main campus of The University of Tennessee at Martin. The researchers created online survey instrument using QuestionPro software to examine perceptions of Residency I candidates. Residency I teacher candidates were asked to complete the surveys at the mid-point of required residency seminars. This studyprovided an analysis of candidate perceptions of a residency model across three campuses of The University of Tennessee at Martin. It sought to examine candidate perceptions and evaluate the following research questions:

Research Question 1: What are teacher candidates' perceptions of a residency program? Research Question 2: What are teacher candidates' perceptions of a pre-residency

program?

Research Question 3: What do teacher candidates' perceive as the values and benefits of the residency program?

Research Question 4: What are teacher candidates' recommendations to strengthen future residency cohorts?

Fifty participants, who were currently enrolled in Residency I courses, were invited to participate in the study; however, only 42surveys were completed in their entirety. All participants were female Early Childhood or Elementary Education candidates. Ninety-four percent of participants will complete their final semester of Residency II in Spring, 2019, with six percent scheduled for completion in Fall, 2019.

\section{Data Analysis}

Immediately following submission of participant surveys, data was analyzed to provide insight into teacher candidates' perceptions of the pre-residency and residency program. Likert-scale survey responses were analyzed using a five-point scale as follows:

- "Strongly Agree" was assigned a point value of " 5 ";

- "Agree" was assigned a point value of "4";

- "Neutral" was assigned a point value of "3";

- "Disagree" was assigned a point value of " 2 "; and

- "Strongly Disagree" was assigned a point value of " 1 ".

Additionally, the open-ended questions revealed several common themes and suggestions about the value of the current program and recommendations to strength future cohorts.

Table 1 provides the results of each Likert-scale item survey item to answer the following:

Research Question 1: What are teacher candidates' perceptions of a residency program? Research Question 2: What are teacher candidates' perceptions of a pre-residency program? 


\section{Table 1 Participants' Residency I Questioning Survey Responses}

\begin{tabular}{|c|c|c|c|c|}
\hline Question & $\mathbf{N}$ & M & SD & $\mathbf{V}$ \\
\hline $\begin{array}{l}\text { As a candidate in Residency I, I was able to participate in all back to school } \\
\text { activities with my CT (Cooperating Teacher). }\end{array}$ & 42 & 4.21 & 1.22 & 1.49 \\
\hline $\begin{array}{l}\text { As part of Residency I, I was able to meet students on the first day of school } \\
\text { alongside my CT. }\end{array}$ & 42 & 4.33 & 1.30 & 1.69 \\
\hline My experiences with my Residency I CT were positive and supportive. & 42 & 4.52 & 0.89 & 0.79 \\
\hline $\begin{array}{l}\text { My experiences with my Residency I CT were informative in that the CT helped } \\
\text { me identify both my areas of strength and of need with regard to my planning, } \\
\text { instructional, assessing, classroom management skills. }\end{array}$ & 42 & 4.10 & 0.91 & 0.82 \\
\hline $\begin{array}{l}\text { The coaching and feedback I received from my instructors during and concerning } \\
\text { my clinical field experience were helpful in strengthening my confidence. }\end{array}$ & 42 & 4.38 & 0.73 & 0.53 \\
\hline $\begin{array}{l}\text { The Residency I model helped prepare me for my edTPA submission (which will } \\
\text { be submitted during Residency II). }\end{array}$ & 42 & 4.07 & 0.95 & 0.90 \\
\hline The Residency I model helped improve my overall learning. & 42 & 4.29 & 0.83 & 0.70 \\
\hline The Residency I model helped improvemy overall preparedness for teaching. & 42 & 4.29 & 0.74 & 0.55 \\
\hline I would recommend the Residency model for future cohorts. & 42 & 4.14 & 0.90 & 0.81 \\
\hline I feel less afraid to stand in front of a classroom of children. & 42 & 4.57 & 0.77 & 0.59 \\
\hline I feel less nervous about someone observing my teaching practices. & 42 & 3.95 & 1.01 & 1.02 \\
\hline I feel more readily able to plan developmentally appropriate lessons/unit starters. & 42 & 4.02 & 0.81 & 0.66 \\
\hline
\end{tabular}

Note: $N=$ number of participants; $M=$ mean; $S D=$ standard deviation; $V=$ variance

Approximately 92 percent (11 out of 12) questions exceeded the four-point threshold, indicating that the majority of teacher candidates perceived both the Pre-Residency and Residency experiences as beneficial. The only indicator that was below the four-point threshold was "I feel less nervous about someone observing my teaching practices" $(m=3.95)$. Students were asked to elaborate on any response that was not Strongly Agree or Agree using an open-ended prompt. The participants who elaborated on their response to this prompt indicated they would continue to be nervous for observations or that there was limited or no feedback from the Cooperating Teacher concerning the quality of the lesson observed.

Additionally, when asked the question, "Do you believe that the Residency model positively impacted your learning experience? Why or why not?" $83 \%$ of respondents stated, "yes" while five participants chose not to respond to this question. Two participants stated that the experience would have been more beneficial if they had been allowed to engage in more classroom activities or have an encouraging Cooperating Teacher.

Qualitative evaluation of participants' open-ended responses provided insight into the following:

Research Question 3: What do teacher candidates' perceive as the values and benefits of the residency program? Research Question 4: What are teacher candidates' recommendations to strengthen future residency cohorts?

Analysis of responses to the question, "Do you believe that the Residency I model positively impacted your learning experience? Why or why not?" revealed two common themes as follows: Theme 1: Participants expressed the value of attending the first days of schools for elementary students and how this experience allowed them to be more prepared for their first teaching assignment. Theme 2: Participants discussed the benefit of increased exposure to "real-world" teaching experience. One teacher candidate stated, "The first days of school and the year-long is a must and a very beneficial change." Another stated, "I feel much more prepared for student teaching and I feel more confident in my methods and content knowledge."

Although the majority of participants believed the Residency model positively impacted their learning experience, several areas of concerns were identified. Recommendations to strengthen future cohorts were consistent among participants and provided the rationale for data-driven changes to the Residency I program as follows:Proposed Change 1: Arrange quality and timely placements with Cooperating Teachers to allow Residency I instructors an opportunity to provide an initial overview of the Pre-Residency expectations for teacher candidates as well as their supervisors. Proposed Change 2: Provide collaborative instruction during the initial days of Residency I to provide consistency in the lesson plan model, task requirements, and edTPA terminology.

Proposed Change 3: Modify assignment expectations for candidates during field experience. 


\section{Summary of Findings}

The purpose of this study was to examine the perceptions of students in our university's initial Residency experience. Four research questions were posed. Research questions 1 and 2 asked participants to reflect on their Residency and pre-residency experiences using a five-point Likert scale. Research questions 3 and 4 were openended questions asking teacher candidates to share strengths of the program and areas that could be strengthened.

Using a Likert-scale, the majority of teacher candidates scored the pre-residency and residency experiences as beneficial. In the qualitative portion of the survey, every teacher candidate shared that the Residency experience was valuable. Teacher candidates shared that the experience of being in the classroom from day one was priceless and provided them with much needed experience. Candidates commented about the importance for them to experience observing how their cooperating teachers established classroom management policies and expectations. Others shared how important it was for them to observe a classroom room for five days a week versus one or two hours per week as in prior courses. Teacher candidates reflected on the actual experiences they participated in during their placement. In addition to planning and teaching lessons, teacher candidates reported participating in grade-level planning meetings, Positive Behavioral Interventions and Support (PBIS) meetings, Individualized Education Program (IEP) meetings, awards programs, and leading Response to Instruction and Intervention $\left(\mathrm{RtI}^{2}\right)$ classes.

While many teacher candidates perceived the residency experience to be valuable, several areas to strengthen were identified. One common area of concern for our teacher candidates was the feeling of being overwhelmed when trying to complete a full residency experience and complete numerous assignments for their coursework. While several teacher candidates shared they felt more confident about having a successful Residency II experience due to the mock edTPA tasks, the amount of coursework and the perceived lack of continuity between instructors was frustrating. To strengthen this area, a proposed change to the program includes a two-week seminar where all residency students will meet together with all the instructors of the courses to collectively learn common academic vocabulary (edTPA), consistent lesson plan expectations and clarify task procedures and expectations.

Although the assignment changes made by the instructors were appreciated, a feeling of frustration permeated the comments. Another shared feeling among teacher candidates was the need for clear expectations prior to their initial placement. Several teacher candidates shared they felt confusion as to what they were to do at the beginning of their placements. Ensuring early placements with high-quality Cooperating Teachers will allow Residency I instructors to meet with teacher candidates prior to Pre-Residency to clarify expectations.

\section{Conclusion}

The teacher residency model holds much promise to address the needs of teacher candidates, as well as create opportunities for extensive field experiences; significantly impacting the preparation of teacher candidates as they prepare to enter their own classrooms as educators. Current research supports the impact clinical field experiences can have on increasing teacher retention, increasing the candidates' ability to integrate theory and practice, and promote gains in student learning. The residency experience helped build candidates' professional capacity through a variety of opportunities - first days of school, IEP meetings, grade level planning meetings, professional development, etc.- that support the growth and development of new teachers. The residency experience supported the development of pedagogical strategies and practice by allowing candidates the opportunity to engage in hands-on teaching experience with the support of mentor teachers in partnering school districts.

First, three consistent areas of improvement were identified by candidates: explicit Residency I expectations for candidates and cooperating teachers, consistency among university faculty assignments and expectations, and the volume of assignments and submission dates during the course of the residency experience. These areas of concerns were identified and recommendations to strengthen future cohorts were considered providing the rationale for the following data-driven changes: arrange quality and timely placements with Cooperating Teachers to allow Residency Ifaculty an opportunity to provide an initial overview of the Residency expectations for candidates and CTs. Additionally, it was noted that university faculty should facilitate collaborative instruction during the beginning of Residency I to provide consistency and clarity in assignments and expectations. 
The need exists for university faculty, school-based administrators, and teachers to share common objectives and goals of clinical field experiences, as well as, how best to support teach candidates (Roegman, Reagan, Goodwin, $\& \mathrm{Yu}, 2016)$. Results from this study support the research and it is apparent that the future residency cohorts must be co-planned, deliberate, and support teacher candidates' development as they become professional educators. The teacher residency model contains elements strengthening the preparation of teachers as they enter the field creating long-term benefits for teacher candidates, districts, schools, and most importantly, the students they serve.

\section{References}

Ewert, G. \& Straw, S.B. (2005). A seven-month practicum: Collaborating teacher's response. Canadian Journal of Education, 28(1\&2).

Gardiner, W. \& Salmon, D. (2014). Faculty research residencies: A response to the problem of enactment. The Professional Educator, 38(1).

Guha, R., Hyler, M.E., \& Darling-Hammond, L. (2017). The power and potential of teacher residencies. Phi Delta Kappan, 98(8).

Hughes, M., \& McCartney, H. (2015). Building Relationships within Extended Field Placements in Elementary Education. Teacher Educators' Journal, 2015, 51-65.

Ingersoll, R., Merrill, L., \& May, H. (2014). What are the effects of teacher education and preparation on beginning teacher attrition? Research Report (\#RR-82). Philadelphia, PA:University of Pennsylvania, Consortium for Policy Research in Education.

Roegman, R., Reagan, E.M., Goodwin, A.L., \& Yu, J. (2016). Support and assist: Approaches to Mentoring in a yearlong teacher residency. International Journal of Mentoring and Coaching in Education, 5(1).

Weber, N.D., Waxman, H.C., Brown, D.B., \& Kelly, L.J. (2016). Informing teacher education through the use of multiple classroom observation instruments. Teacher Education Quarterly. 